\title{
İnsanın Saldırgan ve Şiddet İçeren Davranışlarını Psikoterapi Kuramlarının Ele Alış Biçimlerinin Değerlendirilmesi ${ }^{1}$
}

\author{
DOI: 10.26466/opus.942149
}

*

\author{
Ayşe Cansu Başeğmez ${ }^{*}$ Halis Özerk** \\ * Prof. Dr, İstanbul Kent Üniversitesi, Diş Hekimliği Fakültesi, İstanbul/Türkiye \\ E-Posta: aysecansu.basegmez@kent.edu.tr \\ ORCID: $\underline{0000-0002-2571-5809}$ \\ ** Dr. Öğr. Üyesi, İstanbul Rumeli Üniversitesi, İstanbul/Türkiye \\ E- Posta: halisozerk@halisozerk.com \\ ORCID: 0000-0001-5530-6638
}

Öz

Her yıl, dünya çapinda 1.6 milyondan fazla insan hayatlarm şiddet yüzünden kaybetmekte, daha fazlast ise fiziksel, cinsel, psikolojik ve zihinsel problemler nedeniyle zarar görmektedir. Saldirganlik ve şiddet toplumumuzda da kamusal ya da özel alanda sıklkla sergilenen bir davranış biçimi haline gelmiştir. Günümüzde, azımsanmayacak düzeyde saldırganlık ve şiddetle yüz yüze olunması, süregelmiş kavramlara dair kavrayısıın derinleştirilmesi ve bu davranışlarn psikolojik kökenlerinin analiz edilmesi gerektiŏini göstermektedir. Bu çalısmada psikoterapi kuramlarmın, insanın saldırgan ve şiddet içeren davranışlarına yaklaşımlarının yeniden gözden geçirilerek değerlendirilmesi amaçlanmıştır. Çalışma, nitel bir araştırma olup doküman incelemesi yöntemini içermektedir. İncelenen bilgilerin ışı̆̆ında; psikoterapi kuramlarının herhangi birisinin tamamen haklı ya da haksız olduğunun ileri sürülemeyeceği görülmüştür. Dolayıstyla saldırganlı̆̆ı velveya şiddet davramışıı önlemek ve yerine sağlikl davranışlan oluşturabilmek için gerek bireysel gerek grup psikoterapisi uygulamalarnda, temelde sentezci bir yaklaşımın benimsenmesinin, bireysel ve kültürel unsurlar göz önünde bulundurularak hangi kuramlara daha fazla ağırlk verilmesi gerektiğine karar verileceğinin belirlenmesinin daha sağlıklı bir yaklaşım olacağı kanaatine varılmıştır. Yanısıra bu yaklaşımın, devletin ilgili organlarinca planlanacak ve yürütülecek tüm çalş̧malarda da göz önünde bulundurulmast gerektiği düşs̈nülmüş ve bu bağlamda önerilerde bulunulmuştur.

Anahtar Kelimeler: Psikoterapi, Şiddet, Saldirganlık.

\footnotetext{
1 Bu çalışma, A. Cansu Başeğmez'in Kent Üniversitesi Klinik Psikoloji Yüksek Lisans Programı (Tezsiz) Bitirme Projesi (2019-2020 Bahar Dönemi)'nden türetilmiştir.
} 


\title{
The Evaluation of the Approaches of Psychotherapy Theories to Human Aggressive and Violent Behaviors
}

*

\begin{abstract}
Each year, more than a million people lose their lives, and many more suffer physical, sexual, psychological and mental problems. Aggression and violence have become a frequently exhibited behavior in our society. Facing considerable levels of aggression and violence today suggests that the understanding of ongoing concepts should be deepened and the psychological roots of these behaviors should be reanalyzed. In this study, it is aimed to evaluate psychotherapy theories by reviewing their approaches to human aggressive and violent behaviors. The study is a qualitative research and includes the method of document analysis. In the light of the information examined; it cannot be claimed that any of the psychotherapy theories are completely right or wrong. Therefore, in order to prevent aggression and/or violent behavior and to establish healthy behaviors, it would be healthier to adopt a basically synthesistic approach in both individual and group psychotherapy practices, and to determine which theories should be given more weight by considering individual and cultural factors. In addition, it was thought that this approach should be taken into consideration in all studies to be planned and carried out by the relevant organs of the state, and recommendations were made in this context.
\end{abstract}

Key Words: $\quad$ Psychotherapy, Violence, Aggression. 


\section{Giriş}

Saldırganlık, Türk Dil Kurumu (TDK, 2020) sözlüğünde; “Bireyin kendi düşünce ve davranışlarını dıştaki direnmelere karşı, zorla karşısındakine benimsetme çabası" olarak açıklanmaktadır. Amerikan Psikoloji Birliği (APA) ise saldırganlığ1: "Bireyin diğer birey/bireylere yönelen fiziksel ya da psikolojik zarar verme davranışı" olarak tanımlamaktadır (APA, 2019). Alan yazında, yıkıcılık, saldırganlık ile iç içe geçmiş bir kavram olarak karşımıza çıkmaktadır. Bu nedenle yıkıcılıkla ilgili yapılan araştırmalar da çalışma kapsamına alınmıştır. Yıkıcılık kavramı, APA (2020) tarafından "Saldırganlık davranışını, nesnelere karşı yıkma, zarar verme, bozma eğilimi ile ifade etme durumu" olarak tanımlanmıştır.

Şiddet kavramı ise TDK (2020) tarafından "Karşıt görüşte olanlara kaba kuvvet kullanma/duygu ve davranışta aşırılık" olarak tanımlanırken, APA (1991) şiddeti "Bireylerin ya da grupların, psikolojik, sosyal ya da fiziksel iyi-oluşlarına zarar gelmesiyle sonuçlanan, ani ya da kronik durumlar" şeklinde ifade etmektedir. Dünya Sağlık Örgütü (WHO, 2002)'ne göre ise şiddet; "Bireyin kasıtlı biçimde kendisine, başkasına, bir grup ya da topluluğa karşı, tehdit şeklinde veya gerçek olarak uygulad1ğ1 fiziksel gücün, yaralanma, ölüm, psikolojik zarar, hatalı gelişim ya da yoksunlukla sonuçlanması veya sonuçlanma olasılığının yüksek olması durumu" olarak tanımlanmaktadır.

Saldırganlık ister kişilerarası ilişkilerde sözel ya da fiziksel olarak gerçekleşsin, ister savaşlar ya da katliamlar şeklinde sergilensin dünya tarihi kadar eskidir. Saldırganlığın; spor, ekonomik rekabet, milli savunma ve politika alanlarında sosyal olarak kabul edilebilir biçimleri de bulunmaktadır. Sürekli değişmekte olan dünyanın koşullarından ötürü insanlarda saldırganlığa yol açan etmenler, saldırganlığın çeşitleri ve saldırganlığın sergileniş biçimleri değişkenlik göstermektedir (Breakwell, 1997).

\section{Problem}

Dünyada her yıl 1.6 milyondan fazla insan hayatlarını şiddet yüzünden kaybetmekte, daha fazlası ise fiziksel, cinsel, psikolojik ve zihinsel sağlık 
problemleri nedeniyle zarar görmektedir ve 15-44 yaş arası bireylerde en önde gelen ölüm nedenlerinden biri şiddettir (WHO, 1999).

Saldırganlık ve şiddetin tüm dünyada olduğu gibi Türkiye'de de kamusal ya da özel alanda sıklıkla sergilenen bir davranış biçimi haline geldiği görülmektedir. Yayımlanan bir rapora göre Türkiye'de; evde şiddete tanık olan 12-21 yaş arası ergenlerin oranı \%17 olarak bulunurken, aynı yaş grubunda okulda şiddet tanık olanların oranı \%34, yaşadıkları çevrede şiddete tanık olanların oranı ise \%28 olarak ifade edilmiştir (Çuhadaroğlu ve ark., 2004).

Her ne kadar psiko-sosyal, sosyo-kültürel, nöro-biyolojik ve antropolojik bakış açlarıyla gerçekleştirilmiş pek çok çalışma, saldırganlık, yıkıcılık ve şiddeti anlama çabalarına ışık tutmuş olsa da günümüzde, halen azımsanmayacak düzeyde yaygınlık ve sıklıkta saldırganlık ve şiddetle yüz yüze olunması, yeni verilere ihtiyaç duyulduğunu, süregelmiş kavramlara dair kavrayışın derinleştirilmesi ve bu davranışların psikolojik kökenlerinin analiz edilmesi gerektiğini göstermektedir.

\section{Çalışmanın Amacı}

Bu çalışmanın amacı, psikoterapi kuramlarının, insanın saldırganlık ve şiddet içeren davranışlarına yaklaşımlarının incelenmesi ve değerlendirilmesidir. Çünkü gerek bireysel düzeyde, saldırganlık (yıkıcılık) ve/veya şiddet davranışını sergileyen bireyin rehabilitasyon veya psikoterapi sürecinde terapinin etkinliği, gerekse toplumsal düzeyde saldırganlık ve/veya şiddet davranışını en aza indirgeyip sağlıklı etkileşimleri artırmaya yönelik çalışmalar planlama ve uygulama bakımından psikoterapi kuramlarının saldırganlık, yıkıcılık ve şiddet davranışına yaklaşımlarının yeniden gözden geçirilmesi ve özümsenmesinin yararlı hatta gerekli olacağı kanaati taşınmaktadır.

\section{Önem}

Amaç başlığı altında belirtilen kanaatten hareketle, saldırganlık ve şiddet bağlamında psikoterapi kuramları geçmişten bugüne değişen halleriyle incelenmesi, güncel yeni yaklaşımlarla birlikte ele alınması tartışılması ve yorumlanmasının, alan yazına önemli bir katkı sunacağı düşünül- 
müştür. Aynı zamanda bireysel veya grup psikoterapi uygulayıcılarına uygulamalarını biçimlendirmek veya zenginleştirmek bakımından önemli bir rehber olabileceği öngörülmüştür.

\section{Kuramsal Çerçeve}

Saldırganlık: Giriş kısmında yer verilen uluslararası kuruluşların tanımlarının yanısıra alan yazında saldırganlığın farklı tanımları yapıldığı görülmektedir. Örneğin Freedman (1992) tarafından saldırganlık; başkalarını inciten ya da incitebilecek her türlü davranış şeklidir. Buss ve Perry'e (1992) göre de saldırganlık, diğerlerini incitmeyi ya da onlara zarar vermeyi içeren tutum ve davranışlardır. Varoluşçu Psikiyatrinin/Psikoterapinin önemli uygulayıcılarından May (2019, s.165) ise saldırganlığı; "Düşman olarak görülen kişiye ya da şeye doğru yönelmek, hamle yapmaktır. Amacı, kişinin kendi ya da kendini adadığı şeyin çıkarları için güçte bir değişiklik yaratmaktır. Saldırganlık, gücün yeniden yapılandırılması için bir başkasının alanına giren eylemdir" cümleleriyle tanımlamıştır.

Alan yazında saldırganlığın belli türlere ayrılarak (ya da boyutlar adı altında) incelendiği de görülmektedir. Berkowitz (1993), Bushman ve Anderson (2001) saldırganlığ "Düşmanca saldırganlık" ve "Araçsal Saldırganlık" olarak ikiye ayırmışlardır. Yapılan ayrımlara göre düşmanca saldırganlık; dürtüseldir, plansızdır, düşünmeden gerçekleştirilir, öfkeyle yönlendirilir, hedefe zarar verme nihai amacını taşır ve algılanan kışkırtmaya karşı tepki olarak uygulanır. Araçsal saldırganlık ise; kurbana zarar vermekten daha farklı nihai amaçlara ulaşmak adına tasarlanarak gerçekleştirilir. Örnek vermek gerekirse; hırsızlık ve fiziksel saldırı, her ikisi de kurbana zarar verme amacıyla gerçekleştirilir ancak, hırsızlık nihai hedef olarak kar elde etmeyi taşırken, fiziksel saldırı doğrudan zarar vermeyi amaçlar.

Bazı araştırmacılar tarafından ise bu ayrım "Direkt", "İndirekt" "İlişkisel" ya da "Sosyal" saldırganlık adları verilerek yapılmıştır. Örneğin Archer ve Coyne'a (2005) göre saldırganlık doğrudan olduğunda; kişilerarası çatışma durumlarında sözlü ya da fiziksel olarak zarar vermeyi ifade etmektedir. Buss (1961) ise saldırganlık türlerini 3 boyuta ayırarak kategorize etmiştir: bunlar fiziksel-sözel, aktif-pasif ve direkt-indirekt 
boyutlardır. Fiziksel-sözel boyut saldırganlığı, bir kişinin başka bir kişiye zarar vermek için fiziksel araç veya sözcük kullanıp kullanmadığına göre kategorize eder. Aktif-pasif boyut, saldırganın birisine zarar vermeyi amaçlayan bir davranışta ne ölçüde aktif olarak yer aldığı anlamına gelir; pasif saldırganlık ise, bir şey yapmamak suretiyle zarar vermeyi ifade eder. Ramirez ve Andreu (2003) ise, saldırganlık için, istatistiksel geçerliliğini kanıtladıklarını ileri sürdükleri yeni bir yapısal tipoloji önermiş ve saldırganlı̆̆ın, "biyolojik", "sosyal" ve "durumsal" olmak üzere 3 boyuttan oluştuğunu ifade etmişlerdir. Bu tipolojiye göre fiziksel ve sözel saldırganlık biyolojik boyuta, indirekt saldırganlık sosyal boyuta, araçsal saldırganlık ise durumsal boyuta dahil edilmiştir.

Şiddet: TDK ve APA'nın şiddet tanımlarına ek olarak alan yazında şiddete ilişkin de farklı tanımlar yer almaktadır. Örneğin Michaud (1991, s.10-11) "kişilerarası ilişkilerde, taraflardan biri ya da birkaçının, diğerlerinin bedensel, ahlaki ve ruhsal bütünlügüne, kültürel değerlerine, mallarına, kolektif ya da münferit olarak, doğrudan ya da dolaylı zarar verecek şekilde davranmasıdır" şeklinde tanımlamıştır.

Saldırganlık davranışının farklı adlar altında ele alınmasına benzer biçimde şiddet davranışının da farklı adlar adı altında incelendiği görülmektedir. Ünsal (1996, s.30)' a göre de (Michaud' un tanımından hareketle) iki tür şiddet varlığından söz edilebilmektedir: Birincisi belirli amaçlara ulaşmak için diğerlerine şiddet yoluyla zarar vermeyi ya da caydırıcı olmayı içeren "araç" olarak şiddet, ikincisi ise "dışavurum" olarak şiddettir. Şiddetin uygulanma tipine göre ise şiddetin; fiziksel, cinsel, duygusal, ekonomik ve siber şiddet ayrımlarıyla ele alındığı görülmektedir (Çetiner, 2006; Altun, 2006; Polat, 2016; Gökkaya, 2011; Tamer ve Vatanartıran, 2014).

Yanısıra şiddetin, maruz kalan kişi ya da gruplara göre de kadına yönelik, yaşlılara yönelik şiddet, akran zorbalığı, flört şiddeti, LGBTİ (Lezbiyen, Gay, Biseksüel, Transgender, İnterseks) bireylere yönelik şiddet, mülteci şiddeti ve bireyin kendisine yönelttiği şiddet (intihar) şeklinde sinıflandırıldığ1 görülmüştür (WHO, 2002; Heise ve ark., 1998; (Polat, 2001, s.411-414; Killick ve Taylor, 2009; Kidd ve ark., 2008; 


\section{Psikanaliz ve Psikanalitik Psikoterapiler Açısından Saldırganlık ve Şiddet}

İnsanın saldırganlık ve şiddet içeren davranışlarını inceleyen psikanalitik ve psikanalitik yönelimli psikoterapi kuramlarının bazıları bu davranışların içgüdüsel olduğunu savunurken, diğer kısmı ise bireyde içgüdüsel olarak bulunan yapıcı saldırganlığın birtakım nedenlerle olumsuza evrildiğini ileri sürmektedirler. Bazı psikanalistler ise, saldırganlığın içgüdüsel olduğu düşüncesine karşı çıkmaktadırlar. Psikanalitik yaklaşıma sahip çalışmacıların çoğunluğu, diğer açılardan Freud'a katılmalarına karşın, özellikle metafizik yönü nedeniyle ölüm içgüdüsü kuramını benimsememişlerdir. Ancak, zamanla, libido kavramının karşı ucu olarak bir yıkıcı ölüm içgüdüsünün varlığını kabul ederek bir uzlaşmaya varmışlar ve Freud'un saldırganlık konusuna yaptığı vurguyu kabul etmişlerdir (Fromm, 2011, s.36).

Psikanalitik Kuramın kurucusu Freud' a göre; saldırganlık, yıkıcılık ve şiddet içeren davranışlar insanın doğasında bulunmaktadır. Freud, hemen hemen bütün nevrotik çatışmaların nedenini cinsellikle açıklarken, saldırganlık içgüdüsünü de psiko-seksüel gelişim süreci içinde değerlendirmiştir. Freud, daha sonra, saldırganlığı tepkisel açıdan incelemiş ve bireyin kendini koruma içgüdüsüne bağlamıştır. Bu açıdan, bireyin doyuma ulaşmasını tehdit eden ve engelleyen durumlarda tepki göstereceğini ileri sürerek, bu tepkileri saldırganlık olarak değerlendirilmiştir (Karr, 1971). Freud daha sonraları, saldırganlığı, tamamen biyolojik bir içgüdüye bağlayarak daha katı bir model ortaya koymuştur (Önal, 2011).

Kuramın öncülerinden Adler ise üstünlük isteğini korumak için insan doğasında olumlu şiddet bulunduğunu ileri sürerek, saldırganlığın özsaygının zedelenmesi sonucunda ortaya çıktığını savunmaktadır. Adler, doğduğu andan itibaren çevresindekilerden nefret gören bireylerin gelecekte suça yönelebileceğini, bir kısmının ise içinde oluşan aşağılık duygusunu bastırmak adına, üstünlük kompleksi geliştirerek, içindeki nefreti etrafındakilere yansitabileceğini ileri sürmektedir (Adler, 2000, s.15; Feist ve Feist, 2006, s.82,90).

Kuramın bir başka öncüsü olan Jung, şiddetin kaynağının "gölge arketipi (insanın kendi cinsiyetini temsil eden ve kendi cinsinden kişilerle 
ilişkisini etkileyen prototip)" olduğunu ileri sürmüş ve bireyin, yaşamında zorlandığı bir döneme girdiğinde, bilinçdışında zararsız bir şekilde varolan gölgenin kötü yönlerinin, egonun kontrolü dışına çıkarak saldırgan davranışlara yol açabildiğini ifade etmiştir (Geçtan, 1998, s.177183).

Psikanalitik kuramın öncülerinden ancak aynı zamanda varoluşçu psikoterapiye de yakın olarak kabul edilen Fromm (2011, s.237-247) ise saldırganlığı; "Bir başka insana, hayvana ya da cansız nesneye zarar veren ya da zarar vermeyi amaçlayan hareketler" olarak tanımlamış ve saldırganlığı (şiddeti) "İyi Huylu (Benign)" ve "Yıkıcı (Malignant)" olmak üzere iki başlık altında değerlendirmiştir. İyi huylu saldırganlık; yaşamsal unsurlara yönelen bir tehdit ortaya çıktığında verilen genetik olarak programlanmış bir tepkidir ve bütün hayvanlar ve insanlarda ortak olarak bulunan savunucu bir özellik taşır. İyi huylu saldırganlık türlerinden olan "Sözde saldırganlık" sonuçta zarara yola açabilen ancak başlangıçta böyle bir amaç taşımayan saldırganlıktır ve "Kaza sonucu", spor karşılaşmalarında beceri sergilemek için gerçekleştirilen "Oyunsal" ve "Kendini kabul ettirmeye yönelik" saldırganlık türlerini içermektedir. Y 1 kıcı saldırganlık ise; genetik olarak programlanmış olmayan, savunucu amaçla gerçekleştirilmeyen türde saldırganlıktır ve sadece insana özgüdür. Fromm, şiddeti de türlere ayırarak ele almış şiddetin türleri arasındaki farklılığın da bilinçdışı dürtüler arasındaki farklılıklardan doğduğunu ileri sürmüştür. Fromm'a göre şiddetin en sağlıklı türü “Oyun şiddeti"dir. Bir diğer şiddet türü “Tepkisel şiddet” tir ve bireyin kendisinin ya da başkasının hayatını, şerefini, özgürlügünü ve malını korumak amacıyla yapılır. "Engellenme şiddeti" ise, bireyin herhangi bir ihtiyacı ya da arzusuna ulaşması engellendiğinde ya da kişinin isteyip sahip olamadığı şeylere ulaşmış olan diğer bireylere karşı kıskançlık duyması sonucunda ortaya çıkmaktadır. Tepkisel şiddetin daha sağlıksız şekli "Öç alıcı şiddet"tir. "Ödünleyici şiddet" ise diğer şiddet türlerinin aksine, yaşama değil ölüme hizmet etmekte olan, güçsüzlükten doğup, güçsüzlüğü ödünleyen bir şiddet türüdür. Ödünleyici şiddete çok benzer olan bir başka şiddet türü ise "Sadizm"dir. Sadizm; başkasının üzerinde o kişiye acı çektirmek yoluyla tam bir hakimiyet kurarak, bundan haz almaktır. Fromm, sadistik şiddetin bu kadar güçlü olmasının nedenini 
"Bireyin, yaşamı yaratamadığı için yok etmeye kalkışması" olarak açılamaktadır (Fromm,2011, s.21-253).

Fromm'a (2011, s.21,102,104) göre saldırganlığın içgüdüsel olduğunu düşünen ya da koşullanmayla ortaya çıktığını savunan davranışçı yaklaşımlar, insanı bilinçli ve özgür hareket edebilen bir canlı olarak görmedikleri için doğru değildirler.

Saldırganlığı, psikanalitik bakış açısıyla inceleyenlerden biri olan Winnicott da Freud gibi, saldırganlığın kişiliğin oluşumundan daha önce var olduğunu söyleyen içgüdücü bakış açısını paylaşarak, saldırganlığın işlevsellikle aynı anlama geldiğini ileri sürmüş ancak Freud'a kıyasla, saldırganlı̆̆ın sosyal yönünü daha çok vurgulayarak, doğuştan gelen saldırganlık eğilimlerinin, birey yetişkinliğe doğru ilerlerken şekil değiştirdiğine dikkat çekmiştir (Ünsal, 2011, s.72-74).

Klein (1927) da Freud' un içgüdüsel yaklaşımıyla aynı fikri taşıyarak, saldırganlığın ilk olarak bebeğin bağımlı olduğu nesneye yöneldiğini, sonrasında ise çevresindekilere geçtiğini ifade etmektedir. Çalışmalarında, Freud'un ölüm içgüdüsüne, saldırganlık anlamında geniş bir yer açarak, libido'ya eşdeğer olarak "şükran", thanatos'a eşdeğer olarak ise "haset" sözcüklerini aralarındaki çatışmayı ortaya koyacak şekilde kullanan Klein, hasetin, öfke dolu bir duygu olduğunu, arzulanan nesneyi ona sahip olan diğer kişiden alıp yok etmeye yönelik bir içgüdü olduğunu düşünmektedir. Klein'a göre, bebeklikte iyi nesne ile kurulan bağlantı yeterince güçlü olmadığı durumlarda ise; kişilikte bozulmalar ve psikopatolojik semptomlar gözlenebilmekte, haset ortaya çıkmakta ve yıkıcı eğilimler kuvvet kazanabilmektedir.

Kuramın bir başka öncüsü Horney (2003) ise, ölüm ve saldırganlık içgüdülerini reddederek saldırganlığı, kişinin tehdit dolu bir dünyadaki yalnızlık ve çaresizliğini içeren temel kaygı duygusuna bağlamıştır. Horney'e göre; güven eksikliği ve kaygı hisseden çocuk, çaresizlik ve yalnızlık duyguları ile baş edebilmek için türlü taktikler geliştirerek bunları yetişkinlik dönemine de taşımaktadır. Böylelikle, çevresine düşmanlık geliştirebilmekte ve öç alıcı bir tutum sergileyebilmekte veya kaybettiğini düşündüğü sevgi ve onayı geri kazanabilmek uğruna aşırı uyumlu davranışlara da yönelebilmekte ya da sevilmek için diğerlerine karşı saldırganlaşarak zor kullanabilmektedir. 
Kohut (1977; aktaran, Pulat ve Sarıkaya, 2019, s.91) ise saldırganlığın doğuştan gelen bir içgüdü olmadığını, "narsisistik yaralanma" sonucunda ikincil olarak ortaya çıktığını ifade etmektedir. O'na göre, yıkıcı saldırganlık, kendiliğe yönelik travmatik hayal kırıklığı ve başarısızlıkların çözülmesi sonucu gelişmektedir. Birey çocukluk döneminde annesi tarafından değerli olduğunu hissetmediğinde, gelişimsel bir duraklama yaşar ve saldırganlık duygusu tetiklenir.

Gruen (2015, s.8-90), ebeveyn ile çocuk arasındaki ilişkinin önemini vurgulayarak, sevgisiz ebeveynlerin çocukta yarattı̆̆ meye, otoriteye ve güce tapınmaya, özerk olamamaya, intikam arzusuna, suç işlemeye, sürekli bir düşman imgesi yaratarak, saldırganlığa, şiddet eğilimine, diğer insanlar ve kendisine karşı yıkıcı davranışlara yol açabileceğini ifade etmektedir. Gruen'e göre çocuk, kendisine acı veren ebe-

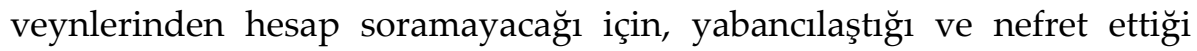
kendiliğinin aynısını gördüğ̈̈ bir başka insana saldırganlık ve şiddet içeren davranışlar sergilemeye başlar.

Ego psikolojisi kuramcları ise öfke gibi davranışların doğal olduğuna dikkat çekerek, bunların denetlenemez (yani içgüdüsel) olmayıp, bireyin seçimlerine bağlı olduklarını ileri sürmektedirler. İnsan davranışlarının tamamını, saldırganlık ve cinsel arzular gibi içgüdüsel dürtülerin ve kontrolündeki zorluklardan ileri gelen gerilimlerle açıklamanın doğru bir yaklaşım olmadığı görüşündedirler (Schultz ve Schultz,2007, s.634).

\section{Davranışçı Psikoterapiler ile Sosyal ve Bilişsel Öğrenme Kuramları Açısından Saldırganlık ve Şiddet}

Watson'un (1914) öncülüğünü yaptığ1 davranışçılığın savunucuları, insanın içsel süreçlerini, ölçülemez olması ve nesnel olmaması nedeniyle kabul etmeyerek, bütün davranışların öğrenme sonucunda gerçekleştiğini ileri sürmektedirler. Davranışı, uyaran ve tepki arasındaki koşullanmayla açıklayan ve insanı doğuştan gelen eğilimlerin değil, yalnızca çevrenin etkisinin biçimlendirdiğini savunan davranışçlar, şiddetin de öğrenildiğini, çevreden olumsuz tepki almadığı ya da teşvik edildiği durumlarda saldırgan davranışı tekrarlayarak alışkanlık haline getireceğini ifade etmektedirler (Fromm, 2011, s.57-71; Eron,1987; Nye, 1998, s.142). 
Skinner ise saldırganlığın, diğer tüm davranış biçimleri gibi, çevresel etkilerin bir sonucu olduğuna dikkat çekerek, kontrol edilebilir olduğunu savunmaktadır (Öğretir-Özçelik, 2017).

Sosyal öğrenme kuramcısı Bandura çocukların saldırgan davranışları başkalarını gözleyerek ve model alarak öğrendiklerini belirtmektedir. Bu görüşünü, "Bobo-doll” (Hacıyatmaz) deneyinde (1961); saldırgan davranışta bulunan bir kişinin elde ettiği sonuçları gözleyen çocukların ya saldırgan davranışı uyguladıklarını ya da saldırgan davranışı yapmaktan kaçındıklarını ortaya koyarak desteklemiştir (Bandura,1977, s.425; Eron,1994, s.3; Saul, 2015).

Bilişsel kurama göre, öfke ve saldırganlık; duygusal, bilişsel ve davranışsal bileşenlerden oluşan bir durum olarak tanımlanmakta ve düşmanca düşünce ve inançlar (bilişsel), öfke duygusuna (duygusal) ve bu da saldırgan davranışa (davranışsal) neden olmaktadır (Beck, 1976; Signorielli, 2005, s.237; Deffenbacher, 2011).

Bilişsel Yeni-Bağlantı Kuramı'na göre ise saldırgan düşünceler, duygular ve davranış eğilimleri hafızada bağlantılı olarak yer almaktadır (Collins ve Loftus, 1975). Saldırganlık davranışının bir grup tarafından gerçekleştirildiği durumlarda, bireysel sorumluluğun hafifleyerek, davranışın grup üyeleri tarafından paylaşıldığı ve sosyal olarak daha kabul edilebilir hale dönüştüğü ifade edilmektedir (Zimbardo, 1969).

\section{Engellenme-Saldırganlık Hipotezi Açısından Saldırganlık ve Şiddet}

Psikanalitik kuram ile davranışçılık arasında köprü kurma çabasıyla Dollard ve arkadaşları tarafından öne sürülen engellenme-saldırganlık hipotezine göre; birey saldırgan davranışa içgüdüsel olarak değil, engellenmenin neden olduğu tepkisel bir dürtü tarafından güdülenmektedir (Dollard ve ark., 1939). Hipotezin savunucuları, her engellenmenin mutlaka saldırganlığa neden olduğu ve saldırganlığın tek sebebinin de engellenme olduğu varsayımlarını zamanla değiştirmiş, bazı ara değişkenler ekleyerek ve bireysel özelliklerin etkilerini de göz önüne alarak yaklaşımını yumuşatmıştır (Berkowitz, 1989). 


\section{Etolojik Kuram Açısından Saldırganlık ve Şiddet}

Etolojik kuram; saldırganlığın enerji birikimi olduğu, yeterince enerji biriktiğinde, bir uyaran olmasa bile (yani dışsal uyarılmaya bağlı olmaksızın da), bir patlamanın meydana gelme olasılığı bulunduğu, düzenli olarak serbest bırakılmadığında bir buhar kazanının patlaması gibi saldırgan davranışlara yol açacağı ve enerji yeniden birikinceye kadar saldırgan davranış oluşmayacağı görüşünü savunmaktadır. Kuramın öncülerinden Lorenz, saldırganlığın insan doğasının bir parçası olması nedeniyle, önlenemeyeceğini ve toplumsal nedenlerle ortaya çıkmayacağını savunmaktadır (Lorenz, 2008, s.413-414).

\section{Varoluşçu Psikoterapi Kuramı Açısından Saldırganlık ve Şiddet}

Kuramın öncülerinden May (2019, s.42-47), saldırganlığın insanın temel donanımının bir parçası olduğunu ve kültür içinde biçim alarak tetiklendiğini ifade etmektedir. May, her insanın yaşamında beş adet güç seviyesi bulunduğunu, ilk üçünün sırasıyla; varolma, kendini onaylama ve kendini ortaya koyma olduğunu, dördüncüsü ve beşincisinin ise saldırganlık ve şiddet olduğunu ifade etmektedir. May'e göre, bireyin varolma, kendini onaylama ve kendisini ortaya koyma gereksinimlerinin uzun süre bastırılması durumunda saldırganlık ortaya çıkmakta ve zamanla önem duygusunu elde etmenin tek yolu şiddet olabilmektedir. May, bu bağlamda, şiddetin gücün fazlalığından çok, güçsüzlükten ileri geldiğini söylemektedir (May, 2019, s.21-39).

Bir başka varoluşçu psikoterapi yaklaşımı olan "Varoluşçu Fenomenolojik Psikoloji", insanların nesnel olarak tanımlanamayacağını, insan deneyiminin başkalarını da içeren bir bağlam içinde gerçekleştiğini ve insanın sosyal çevresinden ayrılamaz olduğunu savunmaktadır (Cooper, 2003). Bu anlamda saldırganlığın, insanların etkileşimlerine, kendilerini içinde buldukları belirli koşullara ve daha geniş kültürel normlara bağlı olarak değerlendirilmesi gerektiği ileri sürülmektedir (Cohn, 1997).

Varoluşçu Psikoterapistlere göre, saldırganlığı patolojik hale getiren bir dünyada saldırgan olmayı seçen bir kişi, sosyal olarak kabul edilebilirliğini sürdürebilmek için, saldırganlığının biyolojik ve/veya çevresel nedenlerini suçlayarak, seçiminin sorumluluğunun kendisinde olduğu- 
nu yadsıyabilmektedir (Fitzpatrick, 2001, s.113). Bireyin, nesneleştirilmiş ve güçsüz olmaktan kaçınmak uğruna, bir mutlak güç arayışına girebileceği ileri sürülmektedir (aktaran, Fletcher ve Milton, 2007). Bu arayış kendisini, diğer canlılar üzerinde saldırganlık yoluyla egemenlik sağlama arzusu olarak gösterebilmektedir (Potter-Efron, 2005).

\section{Hümanistik Psikoterapi Kuramı Açısından Saldırganlık ve Şiddet}

Hümanistik psikoterapi kuramının kurucusu Rogers koşulsuz sevgi ve saygı bulunmayan bir çevrede, bireyin olumlu bir benlik duygusu edinemeyip, normal olmayan davranışlara yönelebileceğini ifade etmektedir. Rogers'a göre insanın yıkıcılığı, temel insani potansiyellerin yerine getirilmesine izin veren koşulların yaratılmamasından kaynaklanmaktadır (Sharf, 2017, s.190; Nye, 1998, s.142).

\section{Evrimsel Psikoloji Kuramı Açısından Saldırganlık ve Şiddet}

Kurama göre, saldırganlık tekil veya üniter bir fenomen olmayıp, aksine, son derece spesifik bağlamsal koşullar altında ortaya çıkan bir strateji koleksiyonunu temsil etmektedir. Saldırganlığın altında yatan mekanizmaların, kaynak sağlama, cinsiyet-içi rekabet, hiyerarşi müzakeresi ve eş bulma gibi bir dizi farklı uyarlanabilir problem için çözüm olarak ortaya çıktığı ifade edilmektedir (Buss ve Shackelford, 1997). Evrimsel psikoloji, erkeklerin daha saldırgan olmalarının, karşılaştıkları daha yoğun üreme rekabetinden kaynaklandığını ve üreme başarılarını artırmak için saldırgan davranışlarda bulunmanın evrimsel olarak bir avantajlı olabileceğini varsaymaktadır.

Psikoterapi kuram ve yaklaşımlarının, saldırganlık ve şiddet içerikli insan davranışını ele alış tarzları ve bunların kökenlerine dair açıklamaları, ulaşılabilen yazılı dokümanlar betimsel tarama (arşiv tarama) yöntemiyle incelenmiştir.

\section{Tartışma}

Psikanalitik ve psikanalitik yönelimli psikoterapi kuramlarının ve kuramcıların, genel olarak, saldırganlık, yıkıcılık ve şiddet içeren davranış- 
ların içgüdüsel olduğunu savunduğu görülmüştür. İçgüdü yaklaşımını destekleyen Winnicott ve Klein gibi bazı psikanalistlerin, saldırganlığın savunma, kendini ifade veya kontrol sağlama gibi farklı amaçlarla başvurulan bir davranış olduğu görüşünde oldukları ya da ölüm içgüdüsünden kaynaklanan saldırganlığın üzerine hasetten doğan saldırganl1ğın eklenmesiyle yıkıcılığın ortaya çıktığını düşündükleri dikkati çekmektedir. Adler ve Fromm gibi bazı psikanalitik yönelimli kuramcıların ise, insanda içgüdüsel olarak bulunduğunu kabul ettikleri yapıcı saldırganlığın, birtakım sebeplerle (öz-saygı zedelenmesi, gelişim dönemlerinde sevgi ve onay görmeme gibi nedenlerle) olumsuza dönüştügünü savundukları görülmüştür.

İnsan ve hayvan davranışlarını karşılaştırmalı olarak inceleyen etolojik kuram ise saldırganlığın aslen dışsal uyaranlara karşı bir tepki değil, insanın içinde gömülü, serbest kalmaya uğraşan ve dişsal uyaranlara bağlı olmaksızın, ortaya çıacak olan, önlenemez bir enerji olduğunu savunmaktadır. Kuram bu haliyle (adına içgüdü demek yerine enerji denmiş olsa da), içgüdü yaklaşımına oldukça yakın olduğunu düşündürmektedir.

İnsan saldırganlığına evrimsel psikoloji penceresinden bakabilmenin ise birçok sınırlamayı içerdiği ve yanısıra birçok şiddet davranışını açıklamakta yetersiz kaldığı görülmektedir. Örneğin eşinin sadakatsizliği ile karşılaşan üç erkekten birinin dayak, ikincisinin cinayet ve üçüncüsünün de sarhoşluk ile tepki vermesinin nedenlerine açıklık getirememektedir.

Bireyin bütün davranışlarının öğrenme ile ve çevrenin şekillendirmesiyle ortaya çıktığını savunan davranışçlar ve sosyal öğrenme kuramc1ları, içsel süreçleri nesnel olmadığı gerekçesi ile kabul etmemekte ve saldırganlık, yıkıcılık ile şiddetin de öğrenilen davranışlar olduğunu düşünmektedirler. Öğrenmenin gelişmiş düzeydeki türlerin davranışında büyük rol oynadığı aşikardır. Son yıllarda yapılan çalışmalar incelendiğinde, sosyal ve bilişsel öğrenme kuramının, saldırganlığın anlaşılması ve kontrol altına alınmasına dair diğer kuramlara oranla daha gözlemlenebilir ve ölçülebilir veriler sağladığı görülmektedir. Ne var ki bu kuramların, saldırgan ve şiddet içeren davranışların nedenleri ve kökenlerini net bir şekilde açıklamakta yetersiz kaldığı durumlar nedeniyle de genellikle psikanalitik ve psikanalitik yönelimli kuramların bu boşluğu doldurduğu görülmüştür. 
Saldırganlığın her zaman engellenmenin sonucu olduğunu savunan engellenme-saldırganlık hipotezinin ise, bireyin saldırgan davranışını içgüdüsel olarak değil, engellenmeye karşı dürtüsel bir tepki şeklinde ele alması yine adına içgüdü denmemiş olsa da fizyolojik bir güdüyü ifade ettiği için bu bağlamda geleneksel psikanalitik yaklaşıma oldukça yakın olduğunu düşündürmektedir. Hipotezin zaten psikanalitik kuramla öğrenme kuramları arasında bir köprü görevi olma amacını taşıdığı göz önüne alındığında bu oldukça anlaşılır bir durumdur. Ancak; insanların engellenmeye karşı gösterdiği tepkilerin, kişiliklere, kültürel ve eğitimsel geçmişlerine bağlı olarak, engellenmeye karşı her zaman saldırganlık şeklinde tepki vermedikleri de ortaya konmuştur (Berkowitz, 1989). Oysa, teori, iki farklı insan aynı hayal kırıklığı uyaranlarını alırsa, benzer veya eşit derecede agresif tepki göstereceklerini varsaymaktadır. Bu bilgilerin ışığında, engellenme-saldırganlık hipotezinin, bireyin öğrenmelerini dikkate almış olsa da insanların bireyselliğini (özellikle kişilik özelliklerini) dikkate almadı̆̆ı söylenebilmektedir.

Davranışçı yaklaşımlar, davranışı öngörmede ve kontrol etmede belirgin bir gelişme sağlamış olmakla birlikte, davranışta bulunan insanın öznelliğini yani kişilik özelliklerini, geçmiş yaşantılarını, varoluşsal unsurları ve kendi değer yargıları ile seçim yapabilme özgürlügüne sahip oluşlarını göz ardı etmeleri nedeniyle saldırganlık ve şiddet davranışını açıklamada beklentileri yeterince karşılayamamaktadır. Bu noktada hümanist ve varoluşçu yaklaşımların açıklamaları daha aydınlatıcı görünmektedir. Hümanistik psikoterapi kuramı, insanı nesnel olarak gören davranışçlığın aksine, bireyin kendi öznel değer yargıları ve seçimleri olduğu görüşündedir. Bu kuram; saldırganlığın tam olarak işlevsel olmayan bireyler tarafından sergileneceğini ve iç dünyalarıyla daha fazla iletişim kuran ve çevrelerindeki dünya hakkında daha net perspektiflere sahip olan bireylerin saldırgan olmalarının pek de olası olmadığını ileri sürmektedir. Bu bilgiler, insan yıkıcılığının önlenebileceğine dair iyimser bir bakış açısı sunmakla birlikte, hümanistik psikoterapi yaklaşımı; otantik ve gerçek deneyimler gibi öznel fikirlerin nesnelleştirilmesinin zor olması ve bir birey için gerçek olan bir deneyimin, bir diğeri için gerçek olmama olasılığı nedeniyle eleştirilmektedir.

Varoluşçu psikoterapi saldırganlık, yıkıcılık ve şiddete varoluşçu felsefe perspektifinden yaklaşmaktadır. Gelişim döneminde sevgi ve onay 
görmüş, öz-saygısı gelişmiş bir bireyin; toplum ve kültür tarafından kabul görmesi halinde, şiddeti her zaman son seçenek olarak düşüneceği ileri sürülmektedir. Bireyin varolma, kendini onaylama ve kendisini ortaya koyma gereksinimlerinin uzun süre bastırılması durumunda ise, önem duygusunu kazanmanın tek yolu saldırganlık ve şiddet olabilmektedir.

Varoluşçu psikoterapi kuramcıları, toplumda gözlenen saldırganlık olgularının genellikle, öz-saygılarını yerleştirmeye ve kendilerinin de önemli olduklarını göstermeye çalışan kişiler tarafından gerçekleştirildiğini ifade etmektedir (May, 2019, s.137,177).

Varoluşçu yaklaşım, insanların nesnel olarak tanımlanamayacağını, insan deneyiminin diğer bireyleri de içeren sosyal bir çevre içinde gerçekleştiğini ve saldırganlığın, insanların etkileşimlerine, kendilerini içinde buldukları belirli koşullara ve daha geniş kültürel normlara bağlı olarak değerlendirilmesi gerektiğini savunmaktadır. Oysa, saldırganlığ 1 açıklamaya çalışan biyolojik ve sosyal-bilişsel modeller, bireyin öznel yönlerini göz ardı ederek, tek taraflı bir saldırganlık profili ortaya koymaktadır. Biyolojik veya çevresel etkenlerin saldırganlığın tek belirleyicisi olarak kabul edilmesinin, nedensel bağlantıların kurulmasında bireyin ve toplumun aktif rolünü tamamen yadsıma riski taşıyacağı ifade edilmektedir (Cohn, 1997).

İncelenip tartışılan bilgilerin ışığında hiçbir kuramın tamamen haklı ya da haksız olduğunun söylenemeyeceği görülmektedir. Dolayısıyla saldırganlığı ve/veya şiddet davranışını önlemek ve yerine sağlıklı davranışları oluşturabilmek için; gerek bireysel gerek grup psikoterapisi uygulamalarında gerekse devletin ilgili organlarınca planlanacak ve yürütülecek tüm çalışmalarda temelde sentezci bir yaklaşımın benimsenmesinde, bireysel ve kültürel unsurlar göz önünde bulundurularak da hangi kuramlara daha fazla ağırlık verilmesi gerektiğine karar verileceğinin belirlenmesinin daha sağlıklı bir yaklaşım olacağı düşünülmektedir.

\section{Öneriler}

1. Başta örgün eğitimin ilk basamaklarından başlayarak tüm basamaklarında, "Dayak cennetten çıkmadır", "Kadının karnından sıpayı, sırtından sopayı eksik etmeyeceksin", "Kızını dövmeyen 
dizini döver", "Hocanın vurduğu yerde gül biter", "On beş yaşındaki kız ya erde gerek ya yerde", "Nush ile uslanmayanı etmeli tekdir, tekdir ile uslanmayanın hakkı kötektir" vb. atasözü ve özdeyişler tartışlarak (örneğin münazara etkinlikleri yoluyla) sağlıksız bilişler sağlıklı bilişlere dönüştürülebilir. Müfredatlarda sağlıklı bilişlere yer verilerek de bu durum pekiştirilebilir.

2. Devlet, ilgili tüm bakanlıkları aracılığıyla bünyelerinde profesyonellerden oluşan komisyonlar kurarak halka yönelik etkinlikler planlayabilir ve gerçekleştirebilir.

3. Radyo ve Televizyon Üst Kurulu (RTÜK)'da da özellikle alanda objektifliği teyit edilmiş psikologlardan (eğitim, sosyal ve klinik alan uzmanı olan psikologlardan), sosyologlardan, eğitimcilerden, halkla ilişkiler ve iletişim alanındaki uzmanlarından oluşan bir komisyon oluşturarak kitle iletişim araçlarında saldırganlığı ve şiddeti besleyen yayınlar yerine sağlıklı davranışlara temel oluşturabilecek programlara yer verilmesini sağlayabilir.

4. Özellikle çocukların saldırganlığı gözlemleyerek öğrendiğinin yapılan çalışmalarla ortaya konduğu göz önünde bulundurularak, başta kitle iletişim araçlarında yer alan programlar (özellikle çizgi filmler) ve eğitsel dokümanlar yine ilgili kurum ve kuruluşlar tarafından denetlenebilir ve sağlıklı hale getirilmesi sağlanabilir.

5. Yetişkin bireylerin saldırgan ve şiddet içerikli davranışları çocukluklarındaki yaşantılarından (ağırlıklı olarak sevgi ve onay eksikliği görmemelerinden) kaynaklı ortaya koydukları gerçeği dikkate alınarak, ebeveynlere yönelik programlar (Anne Baba Okulları, Bilinçli Ebeveynlik seminerleri vb. etkinlikler) hem kamu kurum ve kuruluşlarınca hem yerel yönetimlerce, hem de sivil toplum kuruluşlarınca gerçekleştirilebilir.

Saldırganlığ1 ve şiddeti önleme amacıyla oluşturulmuş tüm sivil toplum kuruluşlarıyla iş birliği içerisinde önleyici ve caydırıcı programlar ve etkin işlevde bulunabilecek kriz merkezleri oluşturulabilir. 
EXTENDED ABSTRACT

\title{
The Evaluation of the Approaches of Psychotherapy Theories to Human Aggressive and Violent Behaviors
}

\author{
* \\ Ayşe Cansu Başeğmez- Halis Özerk \\ İstanbul Kent Univesity- İstanbul Rumeli University
}

Aggression, according to the dictionary of the Turkish Language Association (TDK, 2020), is explained as "an individual's effort to impose his own thoughts and behaviors against external resistances by force". On the other hand, The American Psychological Association (APA) defines aggression as "the physical or psychological harming behavior of an individual directed towards other individual/individuals" (APA, 2019).

While the concept of violence is defined by TDK (2020) as "he use of brute force/excessiveness in emotion and behavior to those who have opposite views", APA (1991) defines violence as "sudden or chronic conditions that result in harm to the psychological, social or physical wellbeing of individuals or groups". According to the World Health Organization (WHO, 2002), violence is defined as "the situation in which the physical force that an individual deliberately exerts against himself, another, a group or community, in the form of a threat or in reality, results or has a high probability of resulting in injury, death, psychological harm, maldevelopment or deprivation".

Each year more than 1.6 million people lose their lives around the world due to violence, and more are harmed by physical, sexual, psychological and mental health problems, and violence is one of the leading causes of death in individuals aged 15-44 (WHO, 1999).

Although many studies conducted with psycho-social, socio-cultural, neuro-biological and anthropological perspectives have shed light on the efforts to understand aggression, destructiveness and violence, today's confrontation with aggression and violence at a substantial level and frequency indicates that new data are needed and underlines the necessity to deepen the understanding of enduring concepts and analyze the psychological origins of these behaviors. 
The aim of this study is to examine and evaluate the approaches of psychotherapy theories to human aggression and violent behaviors. In terms of the effectiveness of the therapy in the rehabilitation or psychotherapy process of the individual who exhibits aggression (destructive) and/or violent behavior at the individual level, and the planning and implementation of studies aimed at minimizing the aggression and/or violent behavior at the social level and increasing healthy interactions, it is believed that it would be useful, even necessary, to re-evaluate and assimilate the approaches the psychotherapy theories to aggression, destructiveness and violence.

It is envisaged that the study will make an important contribution to the literature, as well as being an important guide for individual or group psychotherapy practitioners in terms of shaping or enriching their practices.

In the study, psychotherapy theories and approaches, their ways of handling aggression and violent human behavior and their explanations about their origins, were examined by accessible written documents using descriptive scanning (archive scanning). ,

As a result of the examinations and evaluations it has been observed that psychoanalytic and psychoanalytically oriented psychotherapy theories generally argue that aggressive, destructive and violent behaviors are instinctive. It is noteworthy that some psychoanalysts, such as Winnicott and Klein, who support the instinct approach, hold the view that aggression is a behavior used for different purposes such as defense, selfexpression or control, or that destructiveness arises by adding aggression arising from envy to the aggression stemming from the death instinct. On the other hand, it has been observed that some psychoanalytic theorists such as Adler and Fromm, argue that constructive aggression, which they accept as instinctive in humans, turns into negative due to some reasons (such as damage to self-esteem, lack of love and approval during developmental stages).

Ethological theory, which examines human and animal behavior comparatively, argues that aggression is not primarily a reaction to external stimuli, but an unavoidable energy embedded in humans, trying to be free, and that will emerge regardless of external stimuli. As such, 
the theory suggests that it is quite close to the instinct approach (even though it is called energy instead of instinct).

Behaviorists and Social Learning theorists, who argue that all behaviors of the individual emerge with learning and the shaping of the environment, do not accept internal processes on the grounds that they are not objective, and they think that aggression, destructiveness and violence are learned behaviors. It is clear that learning plays a major role in the behavior of advanced species. When studies conducted in recent years are examined, it is seen that social and cognitive learning theory provides more observable and measurable data compared to other theories on understanding and controlling aggression. However, it has been observed that psychoanalytic and psychoanalytically oriented theories generally fill this gap, since these theories are insufficient to clearly explain the causes and origins of aggressive and violent behavior.

The Frustration-Aggression Hypothesis, which argues that aggression is always the result of frustration, considers the individual's aggressive behavior as an impulsive reaction to frustration, not instinctively. However, although it did not call it instinct, the fact that it expresses a physiological drive with the concept of drive makes us think that the theory is quite close to the traditional psychoanalytic approach. This is quite understandable given that the hypothesis already serves as a bridge between psychoanalytic theory and learning theories. It has also been revealed that people's reactions to frustration, depending on their personalities, cultural and educational backgrounds, do not always react in the form of aggression to frustration (Berkowitz, 1989).

The humanistic psychotherapy theory is of the opinion that aggression and violent behavior are the individual's own subjective value judgments and choices and argues that aggression will be exhibited by fully dysfunctional individuals, and individuals who communicate more with their inner world and have clearer perspectives on the world around them are unlikely to be aggressive. Although the approach of the theory offers an optimistic view that human destructiveness can be prevented, it has been criticized for the difficulty of objectifying subjective ideas such as authentic and real experiences and the possibility that an experience that is real for one individual may not be real for another. 
Existential Psychotherapy theory approaches aggression, destructiveness and violence from the perspective of existential philosophy. An individual who is accepted by society and culture and has received love and approval during the developmental period and has developed selfesteem; he/she will always consider violence as a last option. If the individual's needs for existence, self-affirmation and self-expression are suppressed for a long time, aggression and violence may be the only way to gain a sense of importance.

Existential psychotherapy theorists state that aggression phenomena observed in society are generally carried out by people who try to establish their self-esteem and show that they are also important (May, 2019:137,177).

The existential approach argues that people cannot be defined objectively, that human experience takes place in a social environment that includes other individuals, and that aggression must be evaluated in terms of people's interactions, the specific conditions in which they find themselves, and broader cultural norms.

As a result of the evaluations, it has been seen that no theory can be said to be completely right or wrong.

In order to prevent aggression and/or violent behavior and to create healthy behaviors instead; it is thought that it would be a healthier approach to adopt a synthetic approach in both individual and group psychotherapy practices and in all studies to be planned and carried out by the relevant organs of the state, and to decide which theories should be given more weight, taking into account individual and cultural factors.

It has been suggested that the participation of all public, private and non-governmental organizations in cooperation and through scientific commissions to be formed within their bodies should contribute significantly to the prevention of aggression and violence behaviors. It has been concluded that it is inevitable to place curricula at all stages of education and training and to include programs targeting all individuals of the society through mass media. 


\section{Kaynakça/References}

Adler, A. (2000). Yaşama sanatı. İstanbul: Say Yayınları.

Akgün, S ve Araz, A. (2010). Anlaşmazlıkların çözümü. Ankara: Nobel Yayınları.

Altun, M. (2006). Denizli İli kırsalında bir sağlık ocă̆ı bölgesinde 15-49 yaş evli kadınlarm fiziksel şiddet görme durumları ve kadınların şiddete ilişkin tutumları. Yayımlanmamış Yüksek Lisans Tezi. Pamukkale Üniversitesi, Sosyal Bilimler Enstitüsü, Denizli.

APA (American Psychology Association) (1991). Report of the APA Commission on Violence and Youth. https://www.apa.org/pubs/info/reports/violenceyouth.

APA (American Psychology Association) (2019). Sözlük. https://dictionary.apa.org/aggression. Erişim tarihi: 26/12/2019.

APA (American Psychology Association) (2020). Sözlük. https://dictionary.apa.org/destructiveness Erişim tarihi: 03/01/2020.

Archer, J. ve Coyne, S.M. (2005). An integrated review of indirect, relational and social aggression. Personality and Social Psychology Review, 9(3), 212-230.

Bandura, A. (1977). Social learning theory. Englewood Cliffs, NJ: Prentice Hall.

Beck, A. T. (1976). Cognitive therapy and the emotional disorders. New York: International Universities Press.

Berkowitz, L. (1993). Pain and aggression: Some findings and implications. Motiv. Emot., 17, 277-293.

Berkowitz, Leonard (1989). Frustration-aggression hypothesis: Examination and reformulation. Psychological Bulletin, 106(1), 59-73.

Breakwell, G. M. (1997) Coping with aggressive behaviour. Leicester: BPS Books.

Bushman, B.J. ve Anderson, C.A. (2001). Is it time to pull the plug on the hostile versus instrumental aggression dichotomy? Psychol. Rev., 108, 273-279.

Buss, A. H. and Perry, M. P. (1992). The Aggression Questionnaire. Journal of Personality and Social Psychology, 63, 452-459. https://psycnet.apa.org/record/1993-00039-001.

Buss, A.H. (1961). The psychology of aggression. New York: Wiley.

Buss, D. M. ve Shackelford, T. K. (1997). Human aggression in evolutionary psychological perspective. Clinical Psychology Review, 17(6), 605-619.

Cohn, H. W. (1997). Existential thought and therapeutic practice: An introduction to existential psychotherapy. Thousand Oaks, CA: Sage.

Collins A.M. ve Loftus E.F. (1975). A spreading activation theory of semantic processing. Psychol. Rev., 82, 407-28.

Cooper, M. (2003) Existential therapies. London: Sage Publications. 
Çuhadaroğlu, F., Canat, S., Kılıç, E.Z., Şenol, S., Rugancı, N. ve Öncü, B. (2004). Ergen ve ruhsal sorunları durum saptama çalışması. TÜBA raporları, 4 , Ankara.

Deffenbacher, J. L. (2011). Cognitive-behavioral conceptualization and treatment of anger. Cognitive and Behavioral Practice, 18(2), 212-221.

Dollard, J., Miller, N. E., Doob, L. W, Mowrer, O. H. ve Sears, R. R. (1939). Frustration and aggression. New Haven: Yale University Press.

Eron, L. D. (1987). The development of aggressive behavior from the perspective of a developing behaviorism. American Psychologist, 42(5), 435-442.

Eron, L.D. (1994). Theories of aggression: From Drives to cognitions, aggressive behaviour: Current perspectives. New York: Plenum Press.

Feist, J. and Feist, G.J. (2006) Theories of personality. 6th Edition. New York: McGraw Hill.

Fitzpatrick, M. (2001) The tyranny of health: Doctors and the regulation of lifestyle. London: Routledge.

Fletcher, R. ve Milton, M. (2007) Being aggressive: An existential-phenomenological critique of the psychological literature on Human Aggression Journal of Existential Analysis, 18(2), 297-314.

Freedman, J. (1992). Television violence and aggression: What psychologists should tell the public. In P. Seudfeld, \& P. Tetlock (Eds), Psychology and Social Policy. New York: Hemisphere Publishing Corp.

Fromm, E. (2011). İnsandaki yıkııllı̆̆ı kökenleri. Birinci Kitap. (Çev. Ş. Alpagut). İstanbul: Payel Yayınevi (Orijinal eser 1973 yılında basılmıştı).

Geçtan, E. (1998). Psikanaliz ve Sonrası. İstanbul: Remzi Kitabevi.

Gökkaya, V. B. (2011). Türkiye'de kadına yönelik ekonomik şiddet. C.Ü. İktisadi ve İdari Bilimler Dergisi, 12(2), 101-112.

Gruen, A. (2015). Normalliğin deliliği (Çev. İ. İgan). İstanbul: Çitlembik Yayınları.

Heise, T. (1998) Violence against women, an integrated ecological framework. Violence, 4, 267-290.

Horney, K. (2003). Çağımızın neurotik kişiliği (Çev. B. Kıcır). Ankara: Ege Matbaacllık (Orijinal eser 1937 yılında basılmıştır).

Karr, B. (1971). Freudian aggression theory: Two hypotheses. Psychotherapy: Theory, Research \& Practice, 8(4), 259-263.

Kidd, J. D., Tarynn, A. B., Witten, M. (2008) Transgender and Transsexual identities: The next strange fruit - hate crimes, violence and genocide against the global trans-communities. Journal of Hate Studies, 6(31), 31-63. 
Killick, C., Taylor, J. B. (2009) Professional decision making on elder abuse: Systematic narrative overview. Journal of Elder Abuse and Neglect, 21(3), 21138.

Klein, M. (1927). Criminal tendencies in normal children. British Journal of Medical Psychology, 7, 177-192.

Lorenz, K. (2008). İşte insan. Saldırganlı̆̆ın doğası üzerine (Çev. E. T. Güney). İstanbul: Cumhuriyet Kitapları (Orijinal eser 1963 yılında basılmıştır).

May, R. (2019). Güç ve masumiyet (Çev. M. Doğan). İstanbul: Okuyanus Yayınları (Orijinal eser 1972 yılında basılmıştır).

Michaud, Y. (1991). Şiddet (Çev. C. Muhtaroğlu). İstanbul: İletişim Yayınları (Orijinal eser 1978 yılında basılmıştır).

Nye, R.D. (1998). Three psychologies. Perspectives from Freud, Skinner and Rogers. Belmont: Wadsworth/Thomson.

Öğretir-Özçelik, A. D. (2017). Aggression theories revisited: Lorenz's Neoinstinctivism, Wison's Socio-Biology and Skinner's Behavioral Theories. Journal of Asian Scientific Research, 7(2), 38-45.

Önal, E.E. (2011). Saldırganlık ve saldırganlık nedenlerine ilişkin kuramlar.

https://www.tavsiyeediyorum.com/makale_7195.htm Erişim tarihi: 24/12/2019.

Polat, O. (2016). Şiddet. MÜHF-HAD, 22, 15-34.

Potter-Efron, R. T. (2005) Handbook of anger management. New York: Haworth Press Inc.

Pulat, F., Sarıkaya, M.E. (2019). Insanı anlamanın tarihi. Klasik eserlerin izinde psikoterapi pratiği. İstanbul: Kanon Kitap.

Ramirez, J.M. ve Andreu, J.M. (2003). Aggression's typologies. International Review of Social Psychology, 16, 145-161.

Schultz, D. P. ve Schult, S. E. (2007). Modern psikoloji tarihi (çev. Yasemin Aslay). İstanbul: Kaknüs Yayınları (Orijinal eser 2004 yılında basılmıştır).

Signorielli, N. (2005). Violence in the media: A reference handbook contemporary world issues. California:Abc-Clio.

Tamer, N. ve Vatanartıran, S. (2014). Ergenlerin teknolojik zorbalık algıları. Online Journal of Technology Addiction \& Cyberbullying, 1(2), 1-20.

TDK (Türk Dil Kurumu) (2020). https://sozluk.gov.tr. Erişim tarihi: 03/01/2020.

Ünsal, Artun (1996). Genişletilmiş bir şiddet tipolojisi. Cogito, 6, 29-36.

Ünsal, Z. K. (2011). Winnicott'un kuramında şiddet ve suçluluk. Psikanaliz Yazıları (Psychoanalytic Writings), 23, 71-78.

WHO (World Health Organisation) (1999). Injury: A leading cause of the global burden 
https://apps.who.int/iris/bitstream/handle/10665/66160/WHO_HSC_PVI_99. 11.pdf? sequence $=1 \mathcal{E}$ is Allowed $=y$ Erişim tarihi: 22/12/2019.

WHO (World Health Organisation) (2002). World report on violence and health. https://apps.who.int/iris/bitstream/handle/10665/42495/9241545615_eng.pdf? sequence1 Erişim tarihi: 27/12/2019.

Zimbardo, P. G. (1969). The human choice: Individuation, reason, and order vs. deindividuation, impulse, and chaos. ${ }^{*}$ In W. J. Arnold \& D. Levine (Eds.), Nebraska Symposium on Motivation (p.237-307). Lincoln: university of nebraska press.

\section{Kaynakça Bilgisi/Citation Information}

Başeğmez, A. C. ve Özerk, H. (2021). İnsanın saldırgan ve şiddet içeren davranışlarını psikoterapi kuramlarının ele alış biçimlerinin değerlendirilmesi. OPUS- Uluslararası Toplum Araştırmaları Dergisi, 18(44), 8475-8499. DOI:10.26466//opus.942149. 